\title{
Multi-objective optimization during machining Ti-6Al-4V using nano-fluids
}

\author{
H. Hegab*, W. Abdelfattah, A. Mohany, H. Kishawy \\ Department of Automotive, Mechanical and \\ Manufacturing Engineering \\ University of Ontario Institute of Technology \\ Oshawa, Canada
}

\author{
S. Rahnamayan \\ Department of Electrical, Computer and Software \\ Engineering \\ University of Ontario Institute of Technology \\ Oshawa, Ontario
}

\begin{abstract}
Several properties make titanium and its alloy the primary candidate to attain weight and functional advantages because of its promising properties such as high strength to weight ratio, high corrosion resistivity, and high yield stress. Although titanium alloys have superior properties, some inherent characteristics such as high chemical reactivity and low thermal conductivity lead to poor machinability and result in premature tool failure and shortened tool life. In order to overcome the heat dissipation challenge during machining of titanium alloys, nano-cutting fluids are utilized as they offer higher observed thermal conductivity values compared to the base oil. Thus, in the current work, multi-walled-carbon nanotubes (MWCNTs) cutting fluids along with minimum quantity lubrication (MQL) have been employed during machining Ti-6Al-4V. On the other hand, developing a multiobjective optimization model for machining titanium alloys is a promising step in order to minimize machining cost, achieve excellent surface quality, and increase the cutting tool life by selecting the optimal cutting conditions (i.e. cutting speed, feed rate, depth of cut). In this study, response surface methodology (RSM), and genetic algorithm (GA) are employed to model and optimize three main machining responses: tool wear, surface quality, and power consumption. Three main independent processes parameters are considered when machining titanium alloys, namely; cutting speed, feed rate, and percentage of added nano-additives.
\end{abstract}

Keywords-machining; optimization; modeling; response surface methodology (RSM); nano-cutting fluid; genetic algorithm (GA), NSGA-II

\section{INTRODUCTION}

Titanium alloys are broadly used in various industrial applications in military, aerospace, power generation, automotive, and other fields due to their promising mechanical, physical, and chemical characteristics; such as, high yield strength, high strength to weight ratio, high toughness and high creep, corrosion, and wear resistance [1]. These materials also retain their hardness and strength at high temperatures [2] which make them one of the primary candidates for aerospace, nuclear, power generation, and automotive applications.
However, despite the above-mentioned superior characteristics, titanium alloys are inherently difficult to cut due to their high stresses and high cutting temperatures generated when they are being machined. This is mainly attributed to low thermal conductivity of titanium which adversely affects the tool life and can lead to a premature tool failure. Because of their low thermal conductivity, the generated heat during machining titanium alloys is mainly dissipated through the cutting tool and cooling media other than the workpiece or chip. In addition, titanium alloys become chemically reactive at a high cutting temperature and react with some tool materials which also deteriorate the cutting tool and accelerate the tool failure. Moreover, the resultant chip shape in titanium machining is serrated or saw-toothed as localized adiabatic shear bending and intense shear strain rate exist in the primary shear zone due to the high temperature at the chip-tool interface. Some other properties, which make titanium alloys difficult to cut and impose barriers towards their widespread applications, are low elastic modulus, strain hardening, tendency to adhesion, and forming built-up edges [3, 4].

A promising technology in the application of cutting fluid is known as minimum quantity lubricant (MQL). MQL is a cooling/lubrication method in which an optimal amount of cutting fluid is forced to penetrate into the cutting zone by means of compressed air. Among the available lubrication techniques, the MQL technique with vegetable oil offers the best environmental friendly solution. Not only does this technique provide the optimum amount of lubricant, utilizing vegetable oil presents a promising alternative to overcoming harmful environmental impacts of commercial cutting fluids, such as mineral oil. The major important factor to improve the cooling and lubricant functions in the MQL method is utilizing certain cutting fluids such nano-fluids which can develop its wettability aspects [5, 6]. Carbon nanotubes (CNTs) are among the nanoadditives that have superior properties. The diameters of these nano-additives vary from few nanometers to hundreds of nanometers, and their lengths range between tens of nanometers to several centimeters [7]. Proposing new nano-cutting fluids is contributing to overcome the heat dissipation challenge during the cutting processes as it offers a highly observed thermal conductivity value in comparison with the base lubricants. 
Additionally, it is shown that nano-cutting fluids have superior cooling properties due to its good heat extraction capabilities [8]. Nano-cutting fluids have shown promising effects on the cutting performance characteristics through different cutting operations such as turning, milling and grinding as has been presented in some previous studies [9-14, 22-26]. Also, a previous work introduced a detailed model to assess the sustainability aspects (including cutting fluids application) for machining processes [27]. The proper dispersion of nano-additives into the base cutting fluid shows a promising advantage in cutting processes as it helps to reduce the induced friction between the workpiece and cutting tool [15]. Also, nano-cutting fluids can contribute in facing the heat dissipation challenge during cutting processes. The main objective of this paper is to model and optimize the machining process of Ti-6Al-4V with MQL-nano-fluids using RSM and multi-objective evolution algorithm (i.e., NSGA-II). Three main machining responses are tool wear, surface quality, and power consumption, while three main independent process parameters, as decision variables, are considered during machining titanium alloys as follows: cutting speed, feed rate, and percentage of added nano-additives. The experimental design and methodology will be discussed in the next section, while section 3 will discuss the experimental results, machining responses modeling and multi-objective optimization results. Finally, section 4 will discuss the study conclusions.

\section{EXPERIMENTATION}

In order to investigate the effects of dispersed MWCNTsnano-fluid on the cutting quality performance, experiments are carried out by turning of Ti-6Al-4V. Ti-6Al-4V (UNS R56400) is utilized as the experiments workpiece. The tests are performed on $\mathrm{CNC}$ lathe machine using standard carbide turning inserts CNMG 432MMH13A (ANSI standard). Cutting tests are performed under MQL strategy, using different levels of cutting speed, feed rate, and weight percentages of added nanoadditives. The depth of cut for each cutting pass is $0.2 \mathrm{~mm}$. The cutting tool information is listed in the Table I. Regarding the MQL system, the air-oil mixture was supplied by the stand-alone booster system (Eco-Lubric) installed on the machine tool with a nominal oil flow rate of $40 \mathrm{ml} / \mathrm{hr}$ and air pressure of $0.5 \mathrm{MPa}$. The average surface roughness parameter has been used to evaluate the machined surface quality using a surface roughness tester (i.e., Mitutoyo SJ.201). Through the use of a toolmaker's microscope, flank wear was measured subsequent to each cutting pass. In addition, a Power Sight Manager was employed throughout the machining process in effort to assist with logging power consumption.

TABLE I. THE USED CUTTING INSERT AND TOOL HOLDER DURING MACHINING Ti-6Al-4V

\begin{tabular}{|c|c|}
\hline & $\begin{array}{c}\text { Cutting tool information during machining } \\
\text { Ti-6Al-4V }\end{array}$ \\
\hline Cutting tool & Coated carbide insert (CNMG 120416MR (ISO)) \\
\hline Tool holder & $\begin{array}{c}\text { SANDVICK SCLCR-2525M12 with clearance angle 5o and } \\
\text { rake angle 0o, nose radius of } 1.58 \mathrm{~mm}\end{array}$ \\
\hline
\end{tabular}

Multi-walled carbon nanotubes (MWCNTs) with 13-20 nm average diameter, $95 \%$ purity, $10-30 \mu \mathrm{m}$ length, and $110 \mathrm{~m}^{2} / \mathrm{g}$ specific surface area were used for nano-cutting fluid preparations. Dispersion of MWCNTs into the base cutting fluid is an important factor which affects the resultant nano-cutting fluid thermal conductivity and viscosity. The dispersion of MWCNTs into the base cutting fluid is performed using an ultrasonic device (AQUASONIC-50HT) over the course of 3 hours at $60^{\circ} \mathrm{C}$, which is then followed by a step that offers thorough mixture, using a magnetic stirrer (Hot Plate Stirrer3073-21) for 30 minutes to ensure full dispersion of MWCNTs into the resultant nano-cutting fluid.

In this work, three design variables (i.e., cutting speed, cutting feed, and added nano-additives percentage) are used at three levels each. Table II indicates the design variables studied and the assignment of the corresponding levels. L9 orthogonal array (L9OA) based on the Taguchi method is employed in Table III [16]. Tests are replicated three times and average response values are calculated. The full factorial array in this work is L27OA $\left(3^{3}\right)$; however, fractional factorial array L9OA based on the design of experiments methodology has been employed to save time and cost.

TABLE II. THE LEVELS ASSIGNMENT TO DESIGN VARIABLE

\begin{tabular}{|c|c|c|c|c|}
\hline Design variables & Symbol & Level 1 & Level 2 & Level 3 \\
\hline $\begin{array}{c}\text { Cutting speed } \\
\text { (m/min) }\end{array}$ & A & 120 & 170 & 220 \\
\hline $\begin{array}{c}\text { Feed Rate } \\
\text { (mm/rev) }\end{array}$ & B & 0.1 & 0.15 & 0.2 \\
\hline $\begin{array}{c}\text { Nano-additives } \\
\text { (wt. \%) }\end{array}$ & C & $0 \%$ & $2 \%$ & $4 \%$ \\
\hline
\end{tabular}

TABLE III. THE STUDIED PARAMETER LEVELS AND THE PLAN OF EXPERIMENTS

\begin{tabular}{|c|c|c|c|}
\hline \multirow{2}{*}{$\begin{array}{c}\text { Cutting } \\
\text { test \# }\end{array}$} & $\begin{array}{c}\text { A: Cutting speed } \\
(\mathrm{m} / \mathrm{min})\end{array}$ & $\begin{array}{c}\text { B: Feed rate } \\
(\mathrm{mm} / \mathrm{rev})\end{array}$ & $\begin{array}{c}\text { C: Added } \\
\text { MWCNT } \\
(\text { wt. } \%)\end{array}$ \\
\hline 1 & 120 & 0.1 & 0 \\
\hline 2 & 120 & 0.15 & 2 \\
\hline 3 & 120 & 0.2 & 4 \\
\hline 4 & 170 & 0.1 & 2 \\
\hline 5 & 170 & 0.15 & 4 \\
\hline 6 & 170 & 0.2 & 4 \\
\hline 7 & 220 & 0.1 & 0 \\
\hline 8 & 220 & 0.15 & 2 \\
\hline 9 & 220 & 0.2 & \\
\hline
\end{tabular}

\section{RESULTS AND DISCUSSIONS}

\section{A. Cutting tests results}

The flank wear, surface roughness, and power consumption results are listed as shown in Table IV. Regarding the flank wear results, a maximum flank wear of $0.4 \mathrm{~mm}$ [17] is used as the tool life criteria otherwise, in case of not reaching the end of tool life 
criteria, the cutting stopped after nine cutting passes. Test 3 showed the lowest flank wear value. The cutting conditions at test 3 are cutting speed of $120 \mathrm{~m} / \mathrm{min}$, feed rate of $0.15 \mathrm{~mm} / \mathrm{rev}$ and 4 wt. $\%$ of added MWCNTs. The highest wear value was found after test 8 (after 6 cutting passes) and after test 6 (after 5 cutting passes). Both of cutting tests 8 and 6 have been performed without using nano-additives.

When 2 wt. \% of added MWCNs is utilized, the results showed that cutting test 2 offered the lowest power consumption. The cutting conditions at this test are cutting speed of $120 \mathrm{~m} / \mathrm{min}$ and feed rate of $0.15 \mathrm{~mm} / \mathrm{rev}$. While the highest power consumption value has been obtained at cutting test 8 which has been performed using classical MQL without nano-additives. In general, MWCNTs nano-fluid has shown better performance in reducing the power consumption compared to the tests performed without any nano-additives. For surface roughness results, it is clear that MWCNTs nano-fluid showed promising results to improve the induced surface quality; however, cutting tests 3 and 9 didn't show effective results compared to the other tests performed using nano-additives as these tests have been performed at the higher value of feed rate level (i.e. $0.4 \mathrm{~mm} / \mathrm{rev}$ ). Cutting test 4 showed the best surface quality. The cutting conditions of this test include cutting speed of $170 \mathrm{~m} / \mathrm{min}$, feed rate of $0.1 \mathrm{~mm} / \mathrm{rev}$ and $2 \mathrm{wt}$. \% of added MWCNTs. The obtained results will be used in the next step to build three different mathematical models for the studied machining responses.

TABLE IV. THE MACHINING OUTPUTS RESULTS

\begin{tabular}{|c|c|c|c|}
\hline \multirow{2}{*}{$\begin{array}{c}\text { Cutting } \\
\text { test \# }\end{array}$} & $\begin{array}{c}|c| \\
\mathrm{F}_{1}: \text { Flank wear } \\
(\mathrm{mm})\end{array}$ & $\begin{array}{c}\mathrm{F}_{2} \text { : Surface } \\
\text { roughness } \\
(\mu \mathrm{m})\end{array}$ & $\begin{array}{c}\mathrm{F}_{3} \text { : Power } \\
\text { consumption } \\
(\text { Watt. } \mathrm{h})\end{array}$ \\
\hline 1 & 0.44 & 0.89 & 2325 \\
\hline 2 & 0.18 & 0.85 & 2084 \\
\hline 3 & 0.16 & 1.85 & 2192 \\
\hline 4 & 0.29 & 0.51 & 2138 \\
\hline 5 & 0.21 & 1.063 & 2230 \\
\hline 6 & 0.62 & 2.8 & 2454 \\
\hline 7 & 0.45 & 0.55 & 2634 \\
\hline 8 & 0.56 & 1.89 & 2344 \\
\hline 9 & 0.42 & 1.43 & \\
\hline
\end{tabular}

\section{B. Cutting processes modeling}

The modeling of the studied cutting processes is implemented using response surface methodology (RSM) to study the effects of the studied design variables on the measured responses. RSM has been employed in previous studies to optimize the machining parameters effects on different machining characteristics [18]. The developed models are used to express; the generated power consumption, surface roughness, and flank wear. It should be stated that all studied responses have "lower-the-better" criteria. The purpose of mathematical models relates the process responses to ease the optimization of the process. The model's validation is demonstrated using the average percentage of deviation $(\Delta)$ which can be calculated as shown in equations (1-2) where Rm is the measured response, $R_{p}$ is the predicted response, $n$ is the number of runs, and $\Delta_{\mathrm{i}}$ is the percentage of deviation per run (i).

The developed models using MWCNTs nano-fluid for flank wear, power consumption, and surface roughness are provided as shown in equations (3-5), respectively. The design variables quadratic and interaction effects are used to express the developed model as all studied design variables have three levels ( $2^{\text {nd }}$ degree of freedom). The average model accuracy for the flank wear under using MWCNTs nano-fluid is about $89.31 \%$, while $98.6 \%$ average model accuracy is calculated for the power consumption model, and the surface roughness model provides an average model accuracy of $93.71 \%$. It should be stated that all mathematical models are valid within the studied the range for the independent process parameters

$$
\begin{gathered}
\Delta_{\mathrm{I}}=\operatorname{ABS}\left(\frac{\mathrm{R}_{\mathrm{M}}-\mathrm{R}_{\mathrm{P}}}{\mathrm{R}_{\mathrm{M}}}\right) * 100 \% \\
\Delta=\frac{\sum_{\mathrm{I}=1}^{\mathrm{N}} \Delta_{\mathrm{I}}}{\mathrm{N}}
\end{gathered}
$$

$$
\begin{aligned}
\mathrm{VB}_{1}= & 7.2 * 10^{-6} \mathrm{~A}^{2}+10.96 \mathrm{~B}^{2}+188.6 \mathrm{C}^{2}-7 * \\
& 10^{-3} \mathrm{AB}-2.2 * 10^{-3} \mathrm{AC}-94 \mathrm{BC}+0.22 \\
\mathrm{PC}_{1}= & 0.01 \mathrm{~A}^{2}-2579.76 \mathrm{~B}^{2}+399783 \mathrm{C}^{2}- \\
& 0.35 \mathrm{AB}-75.26 \mathrm{~A}-52343 \mathrm{BC}+2071.63 \\
\mathrm{RA}_{1}= & 8.6 * 10^{-6} \mathrm{~A}^{2}+58.32 \mathrm{~B}^{2}+1480.65 \mathrm{C}^{2}- \\
& 0.002 \mathrm{AB}-0.21 \mathrm{AC}-268.55 \mathrm{BC}+0.27
\end{aligned}
$$

Subjected to the following constraints:

$$
\begin{gathered}
120 \leq \mathrm{A} \leq 220 \\
0.1 \leq \mathrm{B} \leq 0.2 \\
0 \leq \mathrm{C} \leq 0.04 \\
\mathrm{~A}, \mathrm{~B}, \mathrm{C} \geq 0
\end{gathered}
$$




\section{Cutting processes optimization}

In the current study, the non-dominated sorting genetic algorithm (NSGA-II) has been utilized to solve the current multi-objective problem. The NSGA-II $[19,20]$ is one of the popularly used evolutionary multi-objective optimization algorithm which attempt to find optimal Pareto-front solutions. This technique is mainly based on using an elitist principle, and explicit diversity preserving mechanism, called crowding distance. The evolutionary operators of the NSGA-II are based on genetic algorithm's, which are namely cross-over, mutation, and selection. The three mathematical models developed using RSM have been used in the optimization stage.

A constant population size of 50 has been used in this work, while the cross-over rate was 0.8 , and the mutation probability was 0.01 . Tournament selection scheme has been used. Also, an example for the solution converges stages for objective functions 1 and 2 is provided as shown in Figure 2, and The Pareto-front for the three objectives with same GA parameters is provided as shown in Figure 3. The Pareto-front progress is provided as shown in Figure 1. In addition, different values for population number (Np), and cross-over probability $(\mathrm{Cp})$ have been applied to check the results sensitivity, and no significant changes have been observed. Also, a partial consistency between the Paretofront results using different values of population size, and crossover probability with the experimental data has been noticed. The chart for the corresponding design variables with its Paretofront values for each case has been created, and the last case with $\mathrm{Np}=200$, and $\mathrm{Cp}=0.6$ has been presented as shown in Figure 1 and Table V. Depending on the literature review of selecting the optimal machining parameters, and the obtained results from the multi-objective optimization algorithm (i.e., NSGA-II), the optimal machining settings have been chosen.

The optimal levels for cutting speed, feed rate, and the percentage of added nano-additives are obtained at index \#13 (see Table V), which were; $136.5 \mathrm{~m} / \mathrm{min}, 0.123 \mathrm{~mm} / \mathrm{rev}$, and 2.82 wt.\%. Regarding the optimal levels of the nano-additives concertation, it has been found that lowest flank wear has been observed when using 4wt. \% MWCNTs, while the lowest power consumption and surface roughness have been obtained when using 2 wt. \%. On the other hand, the multi-objective algorithm (NSG-II) results showed that the optimal nano-additives concertation was 2.82 wt. \%. The selected optimal level (nanoadditives weight percentage) obtained from optimization procedure provides more physical sense as the highest percentage of nano-additive (4 wt. \%) could cause more deteriorations to the cutting processes because of the highest occurrence possibility of the drastic ploughing effects which could increase the induced nano-additives wear and accordingly increase the overall tool wear. When there is an abundance of nano-additives in the resultant nano-fluid, they collide with and are impeded by the asperities on the work surface and hence stronger cutting forces are generated. As a result, the nanoadditive induced wear is increased with increasing the nanoadditives concretion as similarly discussed in a previous work [21] (see Figure 3). On the other hand, decreasing the nanoadditives concentration would decrease the resultant nano-fluid thermal conductivity and would affect the heat dissipation performance. In addition, decreasing the nano-additives concentration means less nano-additives in the workpieceinterface area, and therefore the induced friction would increase as can be seen in Figure 3. Based on the above explanations, it can be concluded that $2.82 \mathrm{wt}$ \% MWCNTs provides more physical sense as it strikes a balance between achieving reasonable heat transfer performance, and avoiding the drastic ploughing effects.

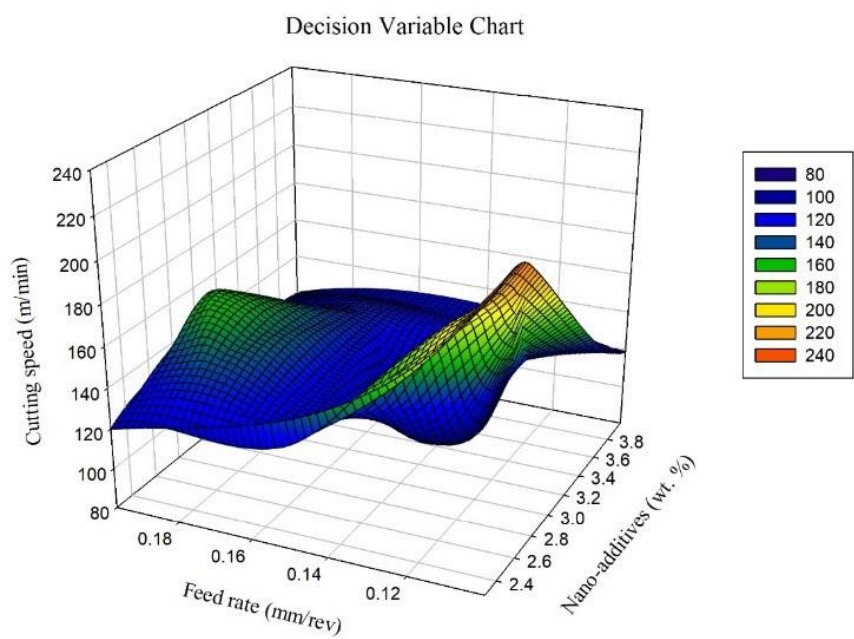

Figure 1. Design variables crosspdoing to the Pareto-front values at $\mathrm{Np}=200$, and $\mathrm{Cp}=0.6$

TABLE V. THE PARETO-FRONT OPTIMAL SOLUTIONS (OPTIMAL SOLUTION VALUES AND CORRESPONDING OPTIMAL DECISION VARIABLES)

\begin{tabular}{|c|c|c|c|c|c|c|}
\hline$\#$ & $\mathbf{F}_{\mathbf{1}}$ & $\mathbf{F}_{\mathbf{2}}$ & $\mathbf{F}_{\mathbf{3}}$ & $\mathbf{A}$ & $\mathbf{B}$ & $\mathbf{C}$ \\
\hline 1 & 0.2538 & 1.609 & 1872.583 & 120.0165 & 0.1976 & 2.28 \\
\hline 2 & 0.1343 & 1.8509 & 1972.339 & 120.0091 & 0.1969 & 3.99 \\
\hline 3 & 0.3865 & 0.3354 & 2220.757 & 216.428 & 0.1007 & 2.33 \\
\hline 4 & 0.3306 & 0.4136 & 2162.84 & 195.3334 & 0.1055 & 2.71 \\
\hline 5 & 0.2014 & 1.3933 & 1915.211 & 156.6597 & 0.1933 & 3.1 \\
\hline 6 & 0.3014 & 0.4721 & 2122.888 & 183.7243 & 0.1146 & 2.34 \\
\hline 7 & 0.1437 & 1.7749 & 1943.891 & 120.0743 & 0.1976 & 3.76 \\
\hline 8 & 0.3664 & 0.3601 & 2197.254 & 209.7226 & 0.1024 & 2.64 \\
\hline 9 & 0.2089 & 1.1313 & 2147.599 & 125.4769 & 0.1254 & 3.77 \\
\hline 10 & 0.1767 & 1.1828 & 2023.023 & 137.7389 & 0.1599 & 3.51 \\
\hline 11 & 0.2645 & 0.5666 & 2090.814 & 169.2304 & 0.1203 & 2.69 \\
\hline 12 & 0.16 & 1.6703 & 1916.766 & 120.6147 & 0.1967 & 3.45 \\
\hline $\mathbf{1 3}$ & $\mathbf{0 . 2 1 7 8}$ & $\mathbf{0 . 7 1 7 1}$ & $\mathbf{2 0 5 9 . 0 1}$ & $\mathbf{1 3 6 . 5 1 1 8}$ & $\mathbf{0 . 1 2 3 2}$ & $\mathbf{2 . 8 2}$ \\
\hline 14 & 0.2149 & 0.9247 & 1981.948 & 130.0624 & 0.1505 & 2.41 \\
\hline 15 & 0.225 & 1.4476 & 1895.653 & 141.7001 & 0.1936 & 2.65 \\
\hline 16 & 0.227 & 1.2574 & 1926.464 & 139.7971 & 0.1798 & 2.5 \\
\hline 17 & 0.2214 & 0.8655 & 1992.583 & 133.2566 & 0.146 & 2.32 \\
\hline 18 & 0.1343 & 1.8509 & 1972.339 & 120.0091 & 0.1969 & 3.99 \\
\hline
\end{tabular}



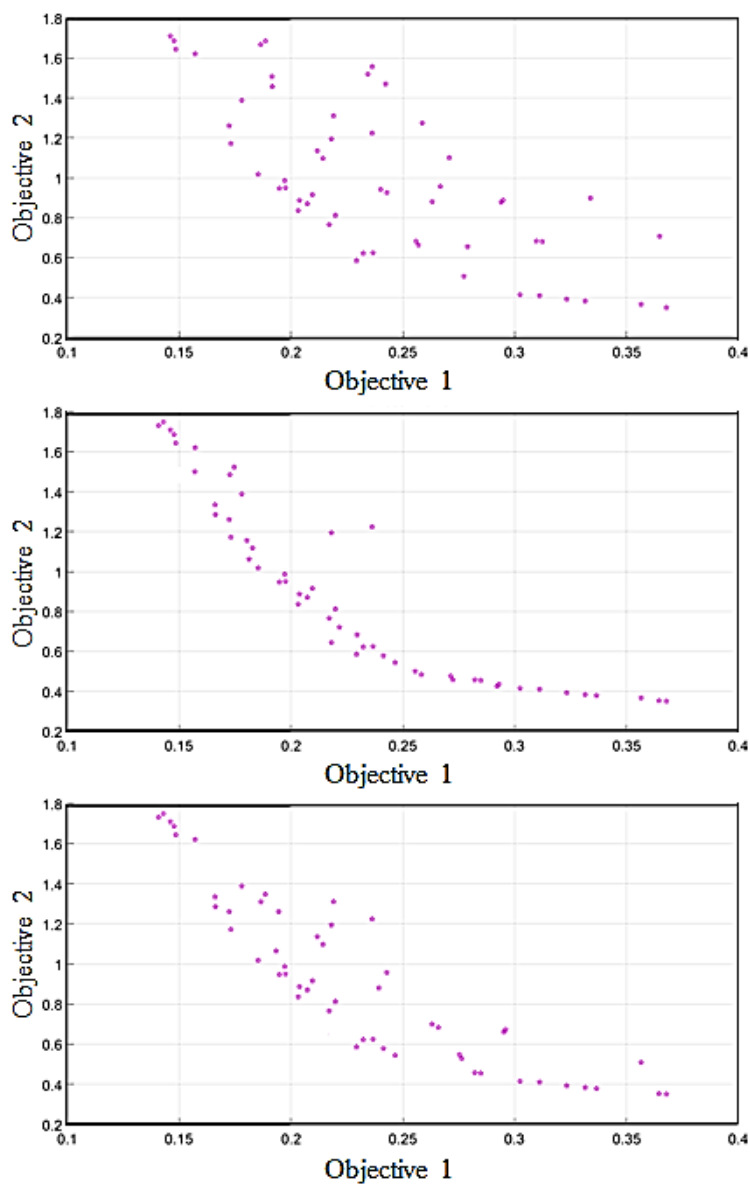

Figure 2. The solution converges stages for objective functions 1 and 2

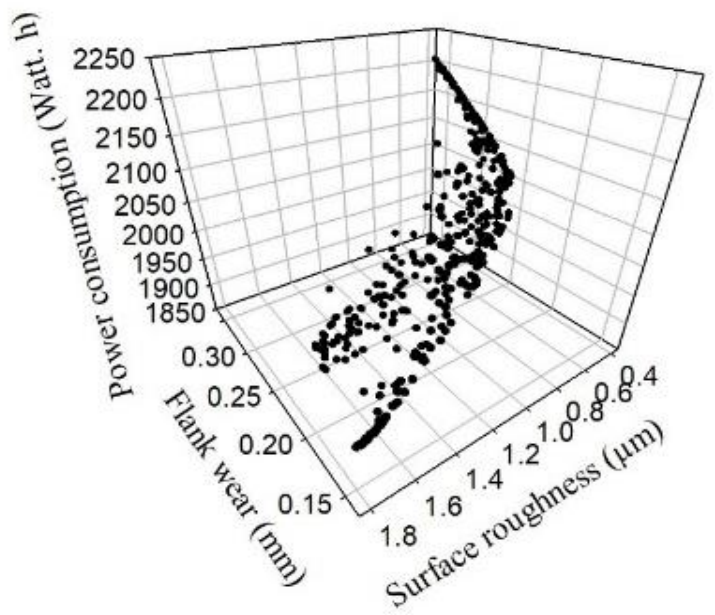

Figure 3. The Pareto-front for the three studied objectives

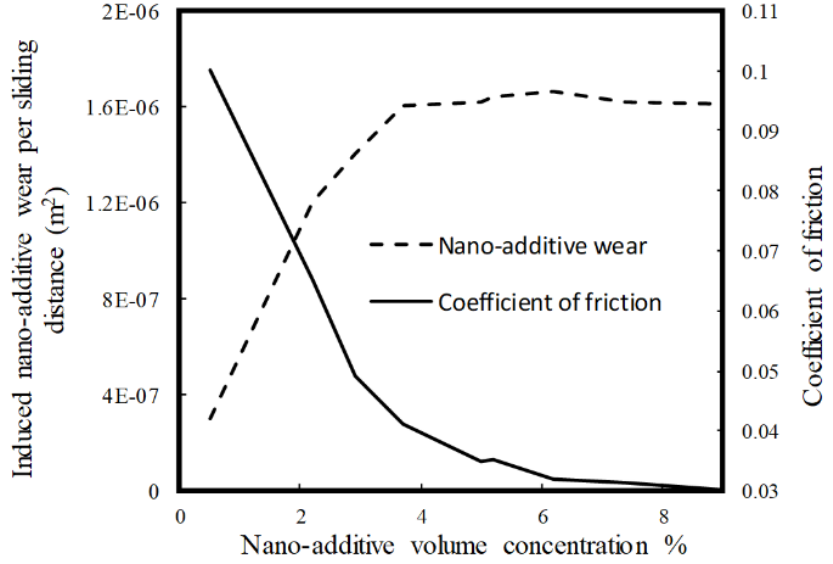

Figure 4. The induced nano-additives wear versus nano-additives concentration [21]

\section{CONCLUSIONS}

In the current work, multi-walled-carbon nanotubes (MWCNTs) cutting fluids along with minimum quantity lubrication (MQL) have been employed during machining Ti$6 \mathrm{Al}-4 \mathrm{~V}$. On the other hand, a multi-objective optimization model has been utilized for machining titanium alloys, which is a promising step in order to minimize machining cost, achieve excellent surface quality, and increase the cutting tool life by selecting the optimal cutting conditions such as cutting speed, feed rate, depth of cut. In this work, MWCNTs nano-fluid showed promising results in enhancing the machining performance during cutting Ti-6Al-4V. It is mainly attributed to the improved heat transfer and tribological characteristics of the employed oil. Also, response surface methodology (RSM), and multi-objective genetic algorithm (NSGA-II) are employed to model and optimize three main machining responses, namely, tool wear, surface quality, and power consumption. Different values for population number, and cross-over probability have been applied to check the results sensitivity; however, no significant changes have been observed. Also, the results showed a partial agreement between Pareto-front solutions using different values of population size, and cross-over probability with the experimental data. Depending on the literature review of selecting the optimal machining parameters, and the obtained results from the multi-objective algorithm, the optimal machining settings have been chosen, as selected solution form Pareto-front set. The optimal levels for cutting speed, feed rate, and the percentage of added nano-additives are obtained at index \#13, which are $136.5 \mathrm{~m} / \mathrm{min}, 0.123 \mathrm{~mm} / \mathrm{rev}$, and $2.82 \mathrm{wt} . \%$, respectively. The selected optimal level (nano- additives weight percentage) obtained from optimization procedure provides more physical sense as it strikes a balance between achieving reasonable heat transfer performance, and avoiding the drastic ploughing effects. Finally, studying and analyzing the MQLnano-fluid tribological and heat transfer mechanisms is still required in order physically obtain the nano- additives size and percentage effects on the cutting processes performance. 


\section{ACKNOWLEDGMENT}

The authors acknowledge the support of the Natural Sciences and Engineering Research Council of Canada (NSERC).

\section{REFERENCES}

[1] Choragudi, A., Kuttolamadom, M. A., Jones, J. J., Mears, M. L., \& Kurfess, T. (2010). Investigation of the machining of titanium components in lightweight vehicles. In SAE International Congress.

[2] Jaffery, S. and P. Mativenga, Assessment of the machinability of Ti-6Al$4 \mathrm{~V}$ alloy using the wear map approach. The International Journal of Advanced Manufacturing Technology, 2009. 40(7-8): p. 687-696.

[3] Ezugwu, E. and Z. Wang, Titanium alloys and their machinability-a review. Journal of materials processing technology, 1997. 68(3): p. 262274.

[4] Shokrani, A., V. Dhokia, and S.T. Newman, Environmentally conscious machining of difficult-to-machine materials with regard to cutting fluids. International Journal of Machine Tools and Manufacture, 2012. 57: p. 83101 .

[5] Amrita, M., R. Srikant, and A. Sitaramaraju, Performance evaluation of nanographite-based cutting fluid in machining process. Materials and Manufacturing Processes, 2014. 29(5): p. 600-605.

[6] Khandekar, S., Sankar, M. R., Agnihotri, V., \& Ramkumar, J. (2012). Nano-cutting fluid for enhancement of metal cutting performance. Materials and Manufacturing Processes, 27(9), 963-967.

[7] Nanomaterials, U.R., US Research Nanomaterials, Inc, The Advanced Nanomaterials Provider. US Research Nanomaterials.

[8] Srikant, R. R., Rao, D. N., Subrahmanyam, M. S., \& Krishna, V. P. (2009). Applicability of cutting fluids with nanoparticle inclusion as coolants in machining. Proceedings of the Institution of Mechanical Engineers, Part J: Journal of Engineering Tribology, 223(2), 221-225.

[9] Sharma, A.K., A.K. Tiwari, and A.R. Dixit, Progress of nanofluid application in machining: a review. Materials and Manufacturing Processes, 2015. 30(7): p. 813-828.

[10] Rajmohan, T., S. Sathishkumar, and K. Palanikumar, Effect of a nanoparticle-filled lubricant in turning of AISI 316L stainless steel (SS). Particulate Science and Technology, 2017. 35(2): p. 201-208.

[11] Singh, R. K., Sharma, A. K., Dixit, A. R., Tiwari, A. K., Pramanik, A., \& Mandal, A. (2017). Performance Evaluation of Alumina-graphene Hybrid Nano-cutting Fluid in Hard Turning. Journal of Cleaner Production.

[12] Bakalova, T., Svobodová, L., Rosická, P., Borůvková, K., Voleský, L., \& Louda, P. (2017). The application potential of $\mathrm{SiO}_{2}, \mathrm{TiO}_{2}$ or $\mathrm{Ag}$ nanoparticles as fillers in machining process fluids. Journal of Cleaner Production, 142, 2237-2243.

[13] Paul, S., A.K. Singh, and A. Ghosh, Grinding of Ti-6Al-4V Under Small Quantity Cooling Lubrication Environment Using Alumina and MWCNT Nanofluids. Materials and Manufacturing Processes, 2017. 32(6): p. 608615.

[14] Liu, G., Li, C., Zhang, Y., Yang, M., Jia, D., Zhang, X., \& Zhai, H. (2017). Process parameter optimization and experimental evaluation for nanofluid MQL in grinding Ti-6Al-4V based on grey relational analysis. Materials and Manufacturing Processes, 1-14.

[15] Alberts, M., K. Kalaitzidou, and S. Melkote, An investigation of graphite nanoplatelets as lubricant in grinding. International Journal of Machine Tools and Manufacture, 2009. 49(12): p. 966-970.

[16] Byrne, D.M., The Taguchi approach to parameter design. Quality Progress, 1987. 20(12): p. 19-26.

[17] Ezugwu, E. O., Da Silva, R. B., Bonney, J., \& Machado, A. R. (2005). Evaluation of the performance of $\mathrm{CBN}$ tools when turning $\mathrm{Ti}-6 \mathrm{Al}-4 \mathrm{~V}$ alloy with high pressure coolant supplies. International Journal of Machine Tools and Manufacture, 45(9), 1009-1014.

[18] Bagaber, S.A. and A.R. Yusoff, Multi-objective optimization of cutting parameters to minimize power consumption in dry turning of stainless steel 316. Journal of Cleaner Production, 2017(157): p. 30-46.

[19] Deb, K., Multi-objective optimisation using evolutionary algorithms: an introduction, in Multi-objective evolutionary optimisation for product design and manufacturing. 2011, Springer. p. 3-34.

[20] Deb, K., Pratap, A., Agarwal, S., \& Meyarivan, T. A. M. T. (2002). A fast and elitist multiobjective genetic algorithm: NSGA-II. IEEE transactions on evolutionary computation, 6(2), 182-197.
[21] Ghaednia, H. and R.L. Jackson, The effect of nanoparticles on the real area of contact, friction, and wear. Journal of Tribology, 2013. 135(4): p. 041603.

[22] Hegab, H., Umer, U., Soliman, M., \& Kishawy, H. A. (2018). Effects of nano-cutting fluids on tool performance and chip morphology during machining Inconel 718. The International Journal of Advanced Manufacturing Technology, 96(9-12), 3449-3458.

[23] Hegab, H., Umer, U., Deiab, I., \& Kishawy, H. (2018). Performance evaluation of $\mathrm{Ti}-6 \mathrm{Al}-4 \mathrm{~V}$ machining using nano-cutting fluids under minimum quantity lubrication. The International Journal of Advanced Manufacturing Technology, 1-13.

[24] Eltaggaz, A., Zawada, P., Hegab, H. A., Deiab, I., \& Kishawy, H. A. (2017). Coolant strategy influence on tool life and surface roughness when machining ADI. The International Journal of Advanced Manufacturing Technology, 1-13.

[25] Hegab, H., Kishawy, H. A., Gadallah, M. H., Umer, U., \& Deiab, I. (2018). On machining of Ti-6Al-4V using multi-walled carbon nanotubes-based nano-fluid under minimum quantity lubrication. The International Journal of Advanced Manufacturing Technology, 1-11.

[26] Eltaggaz, A., Hegab, H., Deiab, I., \& Kishawy, H. A. (2018). Hybrid nano-fluid-minimum quantity lubrication strategy for machining austempered ductile iron (ADI). International Journal on Interactive Design and Manufacturing (IJIDeM), 1-9.

[27] Hegab, H. A., Darras, B., \& Kishawy, H. A. (2018). Towards sustainability assessment of machining processes. Journal of Cleaner Production, 170, 694-703. 